\begin{tabular}{l} 
RACIC 6 (1) (2021) \\
UNIVERSITAS \\
\hline ABDURRAB \\
\hline http://jurnal.univrab.ac.id/index.php/racic
\end{tabular}

\title{
KELAYAKAN TEKNIS PERENCANAAN ANGKUTAN SEKOLAH DI KOTA PEKANBARU
}

\author{
Septia Gusman $^{1}$, Ari Sandhyavitri ${ }^{2}$, Muhammad Ikhsan ${ }^{3}$ \\ ${ }^{1}$ Mahasiswa Magister Teknik Sipil, Universitas Riau \\ ${ }^{2}$ Dosen Magister Teknik Sipil, Universitas Riau \\ ${ }^{3}$ Dosen Magister Teknik Sipil, Universitas Riau \\ J1 Hr Soebrantas Km 12,5 Pekanbaru \\ E-mail: septiagusman@yahoo.com
}

\begin{abstract}
Info Artikel
\section{Abstrak}

Sejarah Artikel:

Di Kota Pekanbaru, perjalanan siswa dari dan menuju sekolah cenderung menggunakan kendaraan pribadi baik itu sepeda motor maupun diantar oleh orang tua sehingga angkutan perkotaan yang tersedia kurang diminati. Hampir $75 \%$ siswa menggunakan sepeda motor, keadaan ini tentunya dapat mempengaruhi

Diterima : 20 Desember 2020

Disetujui : 29 Juni 2021

Dipublikasikan : 30 Juni 2021 keselamatan siswa. Hal ini terlihat dengan adanya angka kecelakaan pada tahun 2017 yang menempatkan profesi pelajar sebagai korban dengan posisi urut ke 2 . Oleh karena itu perlu direncanakan angkutan sekolah yang aman, nyaman, tepat dan selamat. Penelitian ini dilakukan pada sekolah yang berada di Kawasan Kecamatan Lima Puluh.Analisis menggunakan metode perhitungan demand potensial, rute pelayanan, jenis dan jumlah armada.. Berdasarkan permintaan angkutan sekolah, wilayah pelayanan angkutan bus sekolah terbagi menajdi 6 rute angkutan sekolah. Armada yang digunakan adalah bus sedang. Rencana operasional angkutan sekolah dibagi menjadi 3 shift yaitu pagi, siang dan sore.
\end{abstract}

Keywords:

\section{School}

Transportation, Demand Potential, Service Routes, Bus Fleets

Kata kunci: Angkutan Sekolah, Demand Potensial,Rute Pelayanan, Armada Bus

\begin{abstract}
In Pekanbaru City, students' trips to and from school tend to use private vehicles, be it motorbikes or those delivered by parents, so the available urban transportation is less attractive. Almost $75 \%$ of students use motorbikes, this situation can certainly affect student safety. This can be seen from the number of accidents in 2017 which placed the student profession as a victim in the 2 nd position. Therefore, it is necessary to plan safe, comfortable, precise and safe school transportation. This research was conducted at schools in the Lima Puluh District area. The analysis used the method of calculating potential demand, service routes, types and number of fleets. Based on the demand for school transportation, the school bus transportation service area is divided into 6 school transportation routes. The fleet used is medium buses. The operational plan for school transportation is divided into 3 shifts, namely morning, afternoon and evening
\end{abstract}

Keywords : School Transportation, Demand Potential, Service Routes, Bus Fleets 


\section{PENDAHULUAN}

Pelayanan angkutan umum di Kota Pekanbaru masih sangat jauh dari kata optimal, hal ini menjadi salah satu masalah utama di sektor transportasi khususnya transportasi publik. Angkutan umum yang telah beroperasi sekarang masih sangat minim penggunaannya oleh masyarakat. Kemudahan, kecepatan dan kenyamanan saat menggunakan kendaraan pribadi khususnya penggunaan sepeda motor berbanding terbalik dengan pelayanan angkutan umum yang belum mampu memberikan pelayanan tepat waktu. Hal tersebut menjadi faktor pendorong siswa menggunakan kendaraan pribadi. Pelajar di Kota Pekanbaru memilih menggunakan kendaraan pribadi atau diantarkan orang tuanya untuk berangkat ke sekolah dikarenakan banyaknya angkutan perkotaan yang ada di Kota Pekanbaru belum begitu memadai dari segi pelayanan dan rute menuju sekolah yang belum ada. Oleh karena itu, para pelajar sekolah kurang memanfaatkan sarana angkutan yang ada untuk digunakan sebagai transportasi ke sekolah. Permasalahan ini sebaiknya menjadi bahan evaluasi yang harus disikapi oleh Pemerintah agar memberikan pelayanan dalam pemenuhan pelayanan angkutan sekolah. Sarana yang seharusnya disediakan untuk menunjang hal tersebut adalah disediakannya angkutan khusus pelajar atau biasa disebut sebagai angkutan sekolah. Angkutan sekolah yang disediakan ini tentunya harus memiliki aksesibilitas yang tinggi serta pemerataan penumpang. Hal ini tentunya dilakukan agar tidak hanya sebagian pelajar saja yang dapat merasakan angkutan sekolah tersebut. Tujuan dari penelitian ini adalah sebagai berikut :

1. Mengetahui besar demand potensial terhadap angkutan sekolah yang akan dioperasikan pada kawasan pendidikan di Kota Pekanbaru

2. Menetukan rute pelayanan angkutan bus sekolah berdasarkan demand anak sekolah, jenis armada dan jumlah kebutuhan armada angkutan bus sekolah.

\section{TINJAUAN PUSTAKA}

\section{Pengertian Angkutan Sekolah}

Angkutan sekolah adalah angkutan penumpang yang khusus disediakan untuk pelajar sekolah yang digunakan sebagai alat angkutan penumpang khusus dengan dipungut tarif (Wiliam, 1998). Angkutan antar jemput anak sekolah adalah angkutan khusus melayani siswa sekolah dengan asal dan/atau tujuan perjalanan tetap, dari dan ke sekolah yang bersangkutan (SK. 967/A.202/DRJD/2007 Tentang Pedoman Teknis Penyelenggaraan Angkutan Sekolah).

1. Permintaan/demand angkutan sekolah

a. Permintaan angkutan umum Potensial 
Permintaan potensial merupakan jumlah permintaan masyarakat yang menggunakan angkutan umum ditambah dengan jumlah masyarakat yang menggunakan kendaraan pribadi yang berkeinginan melakukan perpindahan keangkutan umum.

2. Perencanaan rute angkutan sekolah

Perencanaan rute angkutan sekolah merupakan hasil observasi awal yang digunakan sebagai acuan dalam perhitungan kebutuhan pelayanan angkutan sekolah di wilayah studi. Dalam merencanakan rute trayek angkutan sekolah melakukan pertimbangan zona asal dan zona tujuan siswa sekolah. Dengan kata lain, permintaan (Demand) yang paling banyak pada zona disesuaikan dengan jaringan lainnya dan mempertimbangkan beberapa aspek berdasarkan Pedoman Teknis Penyelenggaraan Angkutan Sekolah adalah sebagai berikut :

a. Bangkitan dan tarikan perjalanan mempertimbangkan lokasi sekolah;

b. Jenis pelayanan angkutan kota/pedesaan anak sekolah;

c. Kelas jalan yang dilewati sesuai dengan jenis kendaraan yang digunakan;

d. Jarak perjalanan dan waktu tempuh angkutan anak sekolah;

e. Titik awal perjalanan angkutan dimulai; dan

f. Titik centroid masing-masing zona tersebut.

3. Penentuan jenis dan jumlah moda angkutan sekolah

Dalam penentuan jenis dan jumlah moda angkutan sekolah berdasarkan hasil analisis potensi permintaan angkutan sekolah. Selanjutnya jumlah permintaan angkutan sekolah disesuaikan dengan kondisi jalan yang dilalui rute angkutan sekolah, ukuran kota dan kapasitas kendaraan . Indikator kinerja pelayanan angkutan sekolah senagai beirkut :

a. Waktu Operasi Kendaraan

b. Kecepatan Operasi Kendaraan

c. Faktor Muat Kendaraan

d. Waktu Tempuh Kendaraan

e. Waktu Sirkulasi Kendaraan

f. Jumlah Rit

g. Waktu Antar Kendaraan (Headway)

h. Frekuensi Kendaraan

i. Jumlah Kebutuhan Armada

\section{METODE}


Metode penelitian ini ialah diawali dengan pengumpulan data yaitu data primer dan data sekunder. Data primer diperoleh dengan melakukan survei wawancara secara langsung kepada siswa namun karena kondisi sekarang maka survei dilakukan dengan menggunakan google from. Sedangkan untuk data primer diperoleh dengan mendatangi instansi pemerintah dan sekolah yang menjadi objek penelitian untuk mendapatkan poupulasi. Setelah mendapatkan populasi, tentukan sampel. Untuk menentukan sampel dapat menggunakan rumus slovin yaitu sebagai berikut :

Keterangan:

$$
n=\frac{\mathrm{N}}{N d^{2}+1}
$$

$\mathrm{n} \quad=$ Ukuran Sampel

$\mathrm{N} \quad=$ Ukuran Populasi

d = Estimasi Kesalahan $(10 \%)$

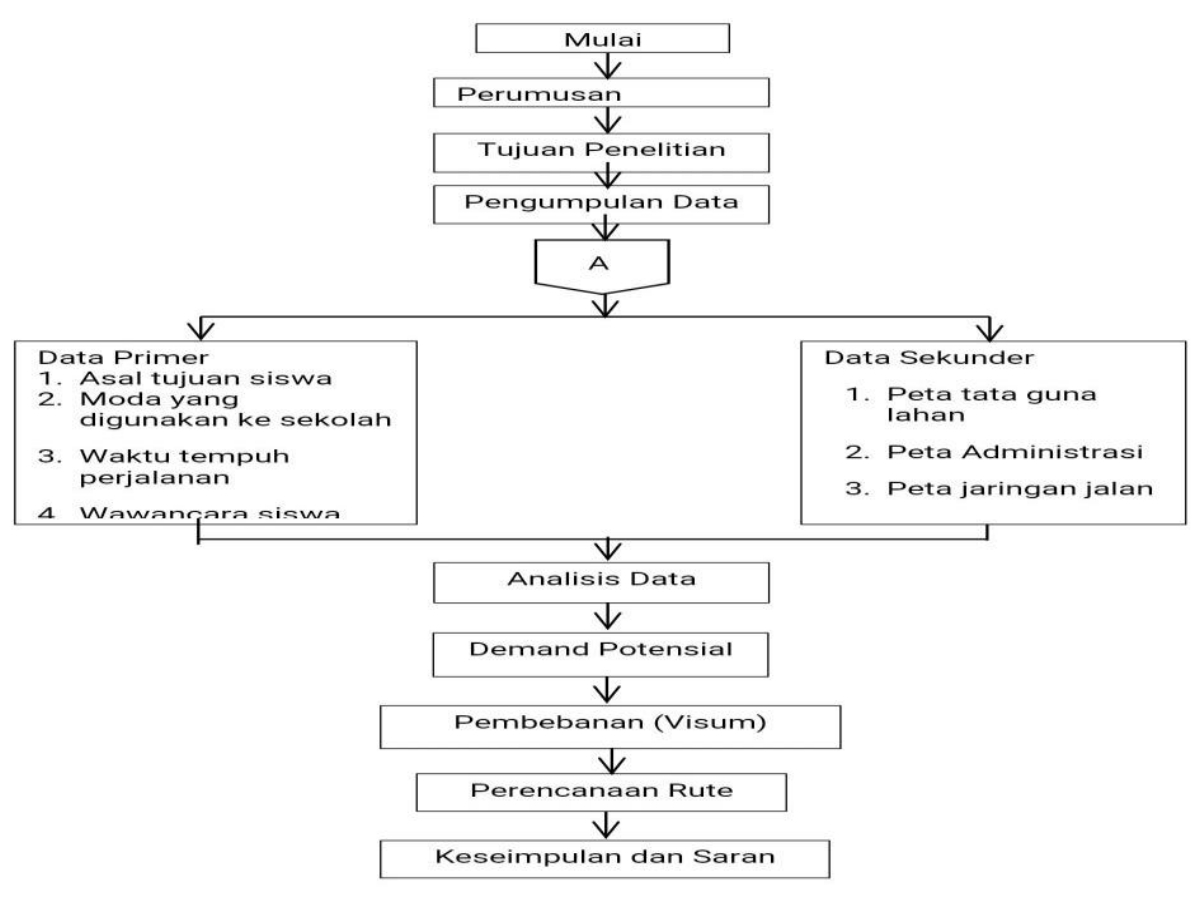

Gambar 1. Bagan Alir Penelitian

\section{HASIL DAN PEMBAHASAN}

\section{Perhitungan Sampel}


Diketahui jumlah populasi jumlah siswa dari sembilan (9) sekolah yang menjadi objek penelitian adalah 7549 siswa. Maka dapat didapat sampel sebesar 99, dimana e = tingkat kesalahan (factor error $=10 \%)$ sebagai berikut :

Tabel IV. 1

Jumlah Sampel Survei Wawancara Tiap Sekolah

\begin{tabular}{cccccc}
\hline NO & NAMA SEKOLAH & POPULASI & PROPORSI & SAMPLE & PEMBULATAN \\
\hline 1 & SMP N 5 PEKANBARU & 818 & 11 & 10,69 & 11 \\
\hline 2 & SMP N 1 PEKANBARU & 611 & 8 & 7,99 & 8 \\
\hline 3 & SMA N 1 PEKANBARU & 1007 & 13 & 13,17 & 13 \\
\hline 4 & SMP N 14 PEKANBARU & 741 & 10 & 9,69 & 10 \\
\hline 5 & SMA HANDAYANI & 808 & 11 & 10,56 & 11 \\
\hline 6 & SMP N 4 PEKANBARU & 1032 & 14 & 13,49 & 13 \\
\hline 7 & SMP N 10 PEKANBARU & 555 & 7 & 7,26 & 7 \\
\hline 8 & SMA N 9 PEKANBARU & 997 & 13 & 13,03 & 13 \\
\hline 9 & SMK 1 PEKANBARU & 980 & 13 & 12,81 & 99 \\
\hline & TOTAL SAMPEL & 7549 & 100 & 99 & \\
\hline
\end{tabular}

Sumber : Hasil Analisis

\section{Demand Potensial}

\section{DEMAND POTENSIAL}

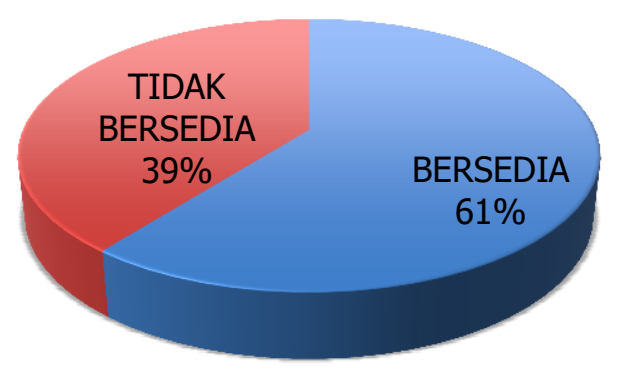


Sumber : Hasil Analisa

Berdasarkan analisa, terdapat $61 \%$ ( 4.652 siswa) yang bersedia pindah ke angkutan bus sekolah dari 9 sekolah yang menjadi objek penelitan.

\section{Perencanaan Rute Angkutan Sekolah}

Berdasarkan hasil pembebanan yang telah dilakukan, penentuan rute angkutan sekolah ditentukan berdasarkan ruas jalan yang memiliki pembebanan tinggi. Masing-masing rute memiliki cakupan wilayah tersendiri dan mewakili permintaan perjalanan berdasarkan hasil pembebanan perjalanan siswa sekolah pada kondisi awal. Keseluruhan dari perencanaan rute tersebut telah disesuaikan dengan pertimbangan - pertimbangan seperti yang telah dijelaskan sebelumnya. Terdapat 6 usulan yang rute yaitu sebagai berikut :

Tabel IV.9

Usulan Rute Trayek Bus Sekolah

\begin{tabular}{|c|c|c|c|}
\hline Rute & Uraian & $\begin{array}{c}\text { Panjang } \\
\text { Rute }(\mathbf{K m})\end{array}$ & $\begin{array}{l}\text { Permintaan Angkutan Sekolah ( } \\
\text { Jumlah Siswa Yang Terangkut) }\end{array}$ \\
\hline (1) & (2) & (3) & $(5)$ \\
\hline 1 & $\begin{array}{c}\text { Pelabuhan sungai duku - Jl. Tanjung } \\
\text { Datuk - Jl. Tanjung Batu - Jl. SSQ - } \\
\text { Kawasan Sekolah }\end{array}$ & 4,2 & 844 \\
\hline 2 & $\begin{array}{c}\text { Jl. Sail - Jl. Satria - Jl. Sungai } \\
\text { Kampar - Jl. Lokomotif - Jl. Tengku } \\
\text { Zainal Abidin - Jl. SSQ - Kawasan } \\
\text { Sekolah }\end{array}$ & 4,3 & 850 \\
\hline 3 & $\begin{array}{c}\text { Jl. Cikditiro - Jl. Jend Sudirman - Jl. } \\
\text { T. Zainal Abidin - Jl. SSQ - Kawasan } \\
\text { Sekolah }\end{array}$ & 3,5 & 732 \\
\hline 4 & $\begin{array}{c}\text { Jl. Bukit Barisan - Jl Imam } \\
\text { Munandar - Jl. Jendral Sudirman - Jl. } \\
\text { Patimura - Jalan Diponegoro - Jl. } \\
\text { Hangtuah - Jl. M. Dahlan -Jl. } \\
\text { Sisingamangaraja - Jl. SSQ - } \\
\text { Kawasan Sekolah }\end{array}$ & 9,8 & 521 \\
\hline 5 & $\begin{array}{c}\text { Jl . Kh Ahmad Dahlan - Jl Tegal lega } \\
\text { - Jl. M yamin - Jl. Jendral Sudirman - } \\
\text { J1 T. Zainal Abidin - Jl. SSQ - } \\
\text { Kawasan Sekolah }\end{array}$ & 5,3 & 730 \\
\hline 6 & $\begin{array}{c}\text { Jl Tenayan - Jl Hangtuah - Jl } \\
\text { Kinibalu - Jl. Sisingamangaraja - Jl. } \\
\text { SSQ - Kawasan Sekolah }\end{array}$ & 8,4 & 876 \\
\hline
\end{tabular}

Sumber : Hasil Analisa

\section{Jenis Armada}




\begin{tabular}{|c|c|c|c|c|}
\hline Rute & Uraian & $\begin{array}{c}\text { Panjang } \\
\text { Rute }(\mathbf{K m})\end{array}$ & $\begin{array}{c}\text { Permintaan } \\
\text { Angkutan } \\
\text { Sekolah }\end{array}$ & Jenis Armada \\
\hline$(1)$ & $(2)$ & (3) & $(4)$ & $(5)$ \\
\hline 1 & $\begin{array}{c}\text { Pelabuhan sungai duku - Jl. Tanjung } \\
\text { Datuk - Jl. Tanjung Batu - Jl. SSQ - } \\
\text { Kawasan Sekolah }\end{array}$ & 4,2 & 844 & Bus Sedang \\
\hline 2 & $\begin{array}{c}\text { Jl. Sail - Jl. Satria - Jl. Sungai } \\
\text { Kampar - Jl. Lokomotif - Jl. Tengku } \\
\text { Zainal Abidin - Jl. SSQ - Kawasan } \\
\text { Sekolah }\end{array}$ & 4,3 & 850 & Bus Sedang \\
\hline 3 & $\begin{array}{l}\text { Jl. Cikditiro - Jl. Jend Sudirman - Jl. } \\
\text { T. Zainal Abidin - Jl. SSQ - } \\
\text { Kawasan Sekolah }\end{array}$ & 3,5 & 732 & Bus Sedang \\
\hline 4 & $\begin{array}{c}\text { Jl. Bukit Barisan - Jl Imam } \\
\text { Munandar - Jl. Jendral Sudirman - Jl. } \\
\text { Patimura - Jalan Diponegoro - Jl. } \\
\text { Hangtuah - Jl. M. Dahlan -Jl. } \\
\text { Sisingamangaraja - Jl. SSQ - } \\
\text { Kawasan Sekolah }\end{array}$ & 9,8 & 521 & Bus Sedang \\
\hline 5 & $\begin{array}{c}\text { Jl . Kh Ahmad Dahlan - Jl Tegal lega } \\
\text { - Jl. M yamin - J1. Jendral Sudirman } \\
\text { - J1 T. Zainal Abidin - Jl. SSQ - } \\
\text { Kawasan Sekolah } \\
\end{array}$ & 5,3 & 730 & Bus Sedang \\
\hline 6 & $\begin{array}{c}\text { Jl Tenayan - Jl Hangtuah - Jl } \\
\text { Kinibalu - Jl. Sisingamangaraja - Jl. } \\
\text { SSQ - Kawasan Sekolah }\end{array}$ & 8,4 & 876 & Bus Sedang \\
\hline
\end{tabular}

Sumber : Hasil Analisa

5. Jumlah Armada

Tabel IV.16

Jumlah Kebutuhsn Armada Masing - Masing Rute

6.

\begin{tabular}{cccccc}
\hline No & Rute & $\begin{array}{c}\text { Waktu } \\
\text { Operasi } \\
\text { (Menit) }\end{array}$ & $\begin{array}{c}\text { Waktu } \\
\text { Tempuh } \\
\text { (Menit) }\end{array}$ & Headway & $\begin{array}{c}\text { Jumlah } \\
\text { Kendaraan }\end{array}$ \\
\hline 1 & $\begin{array}{c}\text { Pelabuhan sungai duku - Jl. Tanjung } \\
\text { Datuk - Jl. Tanjung Batu - Jl. SSQ - } \\
\text { Kawasan Sekolah }\end{array}$ & 60 & 8,4 & 2 & 28 \\
\hline & $\begin{array}{c}\text { Jl. Sail - Jl. Satria - Jl. Sungai Kampar } \\
\text { - Jl. Lokomotif - Jl. Tengku Zainal } \\
\text { Abidin - Jl. SSQ - Kawasan Sekolah }\end{array}$ & 60 & 8,6 & 2 & 28 \\
\hline 3 & $\begin{array}{c}\text { Jl. Cikditiro - Jl. Jend Sudirman - Jl. T. } \\
\text { Zainal Abidin - Jl. SSQ - Kawasan } \\
\text { Sekolah }\end{array}$ & 60 & 7 & 2 & 24 \\
\hline
\end{tabular}




\begin{tabular}{|c|c|c|c|c|c|}
\hline 4 & $\begin{array}{l}\text { Jl. Bukit Barisan - Jl Imam Munandar } \\
\text { - Jl. Jendral Sudirman - Jl. Patimura - } \\
\text { Jalan Diponegoro - Jl. Hangtuah - Jl. } \\
\text { M. Dahlan - Jl. Sisingamangaraja - Jl. } \\
\text { SSQ - Kawasan Sekolah }\end{array}$ & 60 & 19,6 & 2 & 17 \\
\hline 5 & $\begin{array}{l}\text { Jl. Kh Ahmad Dahlan - Jl Tegal lega - } \\
\text { Jl. M yamin - Jl. Jendral Sudirman - Jl } \\
\text { T. Zainal Abidin - Jl. SSQ - Kawasan } \\
\text { Sekolah } \\
\end{array}$ & 60 & 10,6 & 2 & 24 \\
\hline 6 & $\begin{array}{c}\text { Jl Tenayan - Jl Hangtuah - Jl Kinibalu } \\
\text { - Jl. Sisingamangaraja - Jl. SSQ - } \\
\text { Kawasan Sekolah }\end{array}$ & 60 & 16,8 & 1 & 29 \\
\hline
\end{tabular}

\section{SIMPULAN}

Berdasarkan hasil penelitian yang diperoleh maka dapat disimpulkan sebagai berikut :

1. Berdasarkan hasil survei wawancara, diketahui bahwa jumlah demand potensial yaitu sebesar $61 \%$ (4.652 orang) dari jumlah siswa 9 sekolah dalam penelitian ini.

2. Terdapat 6 rute trayek rencana pelayanan angkutan sekolah di Kota Pekanbaru yaitu

a. Rute 1 ( Pelabuhan Sungai Duku - Jl. Tanjung Datuk - Jl. Tanjung Batu - Jl. SSQ Kawasan Sekolah ) dengan panjang rute 4,2 $\mathrm{km}$ dan jumlah armada yang dibutuhkan sebanyak 28 bus sedang

b. Rute 2 ( Jl. Sail - Jl. Satria - Jl. Sungai Kampar - Jl.Lokomotif - Jl. T. Zainal Abidin Jl. SSQ - Kawasan Sekolah ) dgn panjang rute 4,3 km dan jumlah armada yang dibutuhkan sebanyak 28 bus sedang

c. Rute 3 ( Jl. Cikditiro - Jl. Jend. Sudirman - Jl. T. Zainal Abidin - Jl. SSQ - Kawasan Sekolah ) dengan panjang rute 3,5 km dan jumlah armada yang dibutuhkan sebanyak 24 bus sedang

d. Rute 4 ( Jl. Bukit Barisan - Jl. Imam Munandar - Jl. Jend. Sudirman - Jl. Pattimura - Jl. Diponegoro - Jl. Hnagtuah - Jl. M. Dahlan - Jl. Sisingamangaraja - Jl. SSQ - Kawasan Sekolah ) dengan panjang rute 9,8 $\mathrm{km}$ dan jumlah armada yang dibutuhkan sebanyak 17 bus sedang

e. Rute 5 (Jl. KH.Ahmad Dahlan - Jl. Tegal Lega - Jl. M. Yamin - Jl. Jend. Sudirman Jl. T. Zainal Abidin - Jl. SSQ - Kawasan Sekolah) dengan panjang rute 5,3 km dan jumlah armada yang dibutuhkan sebanyak 24 bus sedang

f. Rute 6 (Jl. Tenayan - Jl. Hangtuah - Jl. Kinibalu - Jl. Sisingamangaraja - Jl. SSQ Kawasan Sekolah ) dengan panjang rute $8,4 \mathrm{~km}$ dan jumlah armada yang dibutuhkan sebanyak 29 bus sedang

\section{UCAPAN TERIMA KASIH}


1. Bapak Prof. Dr. Ari Sandhyavitri, M. Sc. selaku Ketua Komisi Pembimbing dan Dr. Muhammad Ikhsan, M. Sc selaku Anggota Komisi Pembimbing, yang telah meluangkan waktu untuk membimbing dan mengarahkan penulis mulai dari awal penelitian hingga selesainya penyusunan tesis ini.

2. Kepada kedua orang tua, suami, anak dan seulurh keluarga atas motivasinya

3. Kepada Dosen-Dosen Penguji yang telah maluangkan waktunya dalam menguji dan memberi saran untuk penyelesaian tesis ini.

4. Seluruh Bapak dan Ibu dosen yang telah memberikan ilmu dan pengetahuannya serta dukungannya kepada penulis selama menjadi mahasiswa di Program Magister Teknik Sipil Universitas Riau.

5. Teman-teman mahasiwa Magister Teknik Sipil Angkatan 2018.

\section{DAFTAR PUSTAKA}

Bowerman, B.L and O'connel, R.T. 1995. Linier Statistical Models Applied Approach. PWSKENT Publishing Company, Boston.

Raco. 2010. Metode Penelitian Kualitatif Jenis, Karakteristik dan Keunggulannya. Gramedia Widiasarana Indonesia. Jakarta.

Sagaya, Syaiful. 2010. Sepervisi Pembelajaran da Profesi Pendidikan. Alfabeta. Bandung.

Sugiyono. 2017. Metode Penelitian Kuantitatif, Kualitatif, dan R\&D. CV Alfabeta,. Bandung.

Suryana. 2010. Metode Penelitian Model Praktis Penelitian Kuantitatif dan Kualitatif. UPI. Bandung.

Wirartha, I Made. 2005. Metodologi Penelitian Sosial Ekonomi. Andi. Yogyakarta.

Mentari. 2016. Implementasi Kebijakan Pengadaan Bus Sekolah Gratis Bagi Pelajar di Kecamatan Mandau Kabupaten Bengkalis. Universitas Riau. Pekanbaru.

Palupiningtyas, Selenia Ediani, Dorkas Pakpahan. 2016. Analisis Kebijakan Penyelenggaraan Angkutan Sekolah di Kota Bandung. Warta Penelitian Perhubungan vol.28 No.2

Setiawan, Surya Shandra. 2016. Evaluasi Program Bus Sekolah di Kota Surbaya. Universitas Negeri Surabaya. Surabaya.

Fitroh, Uswatul. 2017. Efektifitas Pelayanan Angkutan Bus Sekolah Gratis oleh Dinas Perhubungan Komunikasi dan Informatika Kota Blitar. Universitas Negeri Surabaya. Surabaya.

Utami, Dewa Ayu Dwi Wira. 2017. Implementasi Program Angkutan Siswa Trans Serasi dalamMeningkatkan Pelayanan Angkutan Siswa Gratis di Kabupaten Tabanan. E-Jurnal Politika Vol 1 No 1.

Tim PKL. 2018. Laporan Umum Tim PKL Kota Pekanbaru. Pekanbaru 
Republik Indonesia. 2002. Keputusan Dirjen Hubungan Darat No. SK 687 Tahun 2002 tentang Pedoman Teknis Penyelenggaraan Angkutan Penumpang umum di Wilayah Perkotaan dalam Trayek Tetap dan Teratur. Kementrian Perhubungan. Jakarta.

Republik Indonesia. 2007. Keputusan Direktorat Perhubungan Darat No. SK 967 tentang Pedoman Teknis Penyelenggaraan Angkutan Sekolah. Kementrian Perhubungan. Jakarta.

Republik Indonesia. 2009. Undang-Undang No. 22 tentang Lalu Lintas dan Angkutan Jalan. Kementrian Perhubungan. Jakarta.

Republik Indonesia. 2012. Peraturan Pemerintah tentang Kendaraan. Sekretariatan Negara. Jakarta.

Republik Indonesia. 2015. Peraturan Menteri Perhubungan No 29 tentang Standar Pelayanan Minimal Angkutan Orang dengan Kendaraan Bermotor Umum dalam Trayek. Kementrian Perhubungan. Jakarta.

Republik Indonesia. 2018. Peraturan Menteri Perhubunga Nomor 117 tentang Penyelenggaraan Angkutan orang tidak dalam Trayek. Menteri Perhubungan. Jakarta. 